\title{
STURGE-WEBER SYNDROME: A TYPE OF PHAKOMATOSIS
}

Shruti S. Patil ${ }^{1}$, Ravi Raja Sankuri²

\section{HOW TO CITE THIS ARTICLE:}

Shruti S. Patil ${ }^{1}$, Ravi Raja Sankuri. "Sturge-Weber Syndrome: A Type of Phakomatosis". Journal of Evolution of Medical and Dental Sciences 2014; Vol. 3, Issue 54, October 20; Page: 12523-12525,

DOI: $10.14260 /$ jemds/2014/3659

INTRODUCTION: Sturge-Weber syndrome (SWS) (MIM ID 185300) (ORPHA 3205) (ICD 10 code Q85.8) or encephalotrigeminalangiomatosis belongs to group of disorders collectively called asphakomatoses ("mother-spot" disease). This rare congenital neurocutaneous syndrome is characterized by unilateral facial cutaneous vascular malformations affecting the eye and skin in association with ipsilateralleptomeningealangiomatosis.[1,2] In 1860, Schirmer first identified this syndrome, and Sturge in 1879 described it in detail; later Frederick Parkes Weber in 1992 demonstrated intracranial calcification. ${ }^{[1,2]}$ The prevalence of the diseases 1:50,000 live birth sand equally affects males and females with no racial predilection. ${ }^{[2]}$

KEYWORDS: port-wine, stain, angiomatosis, sturge-weber syndrome, dimitri disease.

CASE SUMMARY: A 39 years old female patient was admitted for seizures one week back. There was no history off ever, altered sensorium, head injury or difficulty in vision. History of similar episodes of seizures was present since 2 years of age and patient was on anticonvulsant therapy. Also there was history of right hemiparesis since 3years for which she is on treatment. There was no significant illness in the past. General examination revealed no significant abnormal it except a reddish pink nevus was present over forehead vertical, slightly left to midline since birth. (Fig. 1) The systemic and oral cavity examination was normal. On investigation, patient's ECG, chest X-ray, blood investigations were within normal limit. Ophthalmologic examination didn't reveal glaucoma. Plain x-ray of skull revealed wavy, gyriform calcifications intra cranially. (Fig 2 \& Fig 3) CT brain showed a tram-track pattern of calcification with atrophied left cerebral hemisphere and hyper-pneumatised left frontal sinus. MRI confirmed the hemi-cerebral atrophy and calcifications showed blooming on GRE sequence with enlarged ipsilateral choroid plexus. MR venography showed hypoplastic ipsilateral cortical venous system. Patient was treated conservatively and advised regular follow up.

DISCUSSION: Sturge - Weber syndrome (OMIM-185300) is an uncommon nonhereditary developmental condition with neurological and skin disorder. It is also known as Sturge-Weber disease, encephalotrigeminal angiomatosis, meningofacial angiomatosis, and Sturge - Weber Dimitri syndrome.[3] It is a sporadically occurring, frequently progressive, congenital neurocutaneous syndrome often associated with epilepsy which belongs to a group of disorders collectively known as 'Phakomatoses' or 'Mother-spot disease 'but in contrast to the other disorders (Neurofibromatosis, Tuberous sclerosis and von Hippel-Lindau disease), in this group, there is no evidence of heredity.

The possibility of a somatic mutation being present in SWS is based on the finding of an increased gene expression offibronectinfrom port-wine stain (PWS) fibroblasts when compared to fibroblasts from normal skin in the same patient. The somatic mutation in the precursors of some angiogenic factors may lead to their over production, producing angiomas or due to a lethal gene surviving by mosaicism. ${ }^{[4]}$ SWS occur with a frequency of approximately 1:50,000 live births. 
The typical patient presents at birth with facial angiomas, however the reverse is not always true. In the incomplete form of Sturge-Weber syndrome, central nervous system angiomas occur without cutaneous manifestations, thus no suspicion of the syndrome arises until the onset of seizures. [5] Angiomas of SWS result due to failure of regression of a vascular plexus around cephalic portion of neural tube which is destined to become facial skin. This vascular plexus normally forms at the $6^{\text {th }}$ week of intrauterine life and regresses by $9^{\text {th }}$ week. Failure of its regression results in residual vascular tissue which forms angiomatous malformations of leptomeninges, face and ipsilateral eye. [6]

There may be seizures, developmental delay and mental retardation if angiomas involve a greater part of brain. The seizures of the contralateral side to the PWS may begin in infancy and worsen with age, eventually occurring in 75\% cases. Mental retardation may be progressive but is not related to the seizure severity or frequency. Patients affected with the syndrome present a variety of orofacial clinical manifestations including gingival haemangiomatous lesions, labial angiomas and nasal septum deviation. [7] SWS is evident at birth as a unilateral PWS on the forehead and upper eyelid in the region supplied by the first branch of the trigeminal nerve, and varies in color from pink to red to purple in color. $50 \%$ of the affected children will have or develop glaucoma. Glaucoma may usually occur when PWS involves the eyelids.[8]

The diagnosis is based on clinical and imaging studies. Skull films may reveal tram track calcification caused by calcification in gyri, ipsilateral calvarial thickening and enlargement of the paranasal sinuses and mastoid. Cranial CT scan revealing cortical atrophy underlying the angioma with gyriform' tram-track' calcifications is the characteristic imaging feature. MRI is the current gold standard for diagnosis of the disease which is reliable even in very young infants. ${ }^{[9]}$ New born babies with a PWS should have an ophthalmological examination in the first month of life, followed by neuroimaging (CT and gadolinium enhanced MRI) by 6-12 months age or sooner if neurologic signs are present. Months age or sooner if neurologic signs are present. Cerebral blood flow imaging, Single Photon Emission Computed Tomography (SPECT) and Positron Emission Tomography (PET) are also useful when possible.

The neurological signs are due to ipsilateralleptomeningealangioma involving the occipital and posterior parietal lobes of the brain; vascular stasis with resultant is chaemialeads to calcification and laminar cortical necrosis. Management of the syndrome involves both medical and surgical approaches. Medical treat men includes anticonvulsant therapy with prophylactic low dose aspirin to prevent thrombus formation. Acute treatment of seizures with benzodiazepines or if ineffective, intravenous phenytoin or phenobarbitone is recommended in India. ${ }^{[10]}$ PWS may be treated with cosmetic camouflage creams, Pulsed dye laser and cosmetic surgery. Early surgery is advocated for better seizure control and to prevent developmental delay.[11] Behavioral problems may be encountered either due to previous exposure to hospital settings or due to mental impairment which demands the use of behavioral management techniques.

CONCLUSION: The diagnosis and treatment of Sturge - Weber Syndrome relies on a detailed history, thorough clinical examination and imaging, requiring a multidisciplinary approach and coordination between different fields of medicine, surgery and dentistry. The importance of new born diagnosis and further multi Centre clinical investigation as well as continuing genetic research is essential in SWS Determining the underlying cause of SWS is a difficult problem but further research in the area would allow an increase in understanding and application of new treatment options. 


\section{REFERENCES:}

1. N C Gill, N Bhaskar. Sturge-Weber syndrome: a case report. Contemporary Clinical Dentistry 2010; 1 (3): 183-185.

2. Z Jing, L Nan-yan, Z Xiao-jun, W Jian-dong, M A Heng - hui, Z Ru-song. Sturge-Weber syndrome: a case report and review of literatures. Chinese Medical Journal, vol. 123, no. 1, pp. 117-121, 2010.

3. P Babaji, M A Prasanth, B C Manjunath, R Vatsala, N Sharma. Sturge-Weber syndrome in association with Pyogenic granuloma: a case report. Journal of International Dental and Medical Research, vol. 5, pp. 41-44, 2012.

4. Rajendra R. "Benign and malignant tumors of oral cavity" In: Shafer, Hine, Levy textbook of oral pathology, fifth edition 2006 p. 204-205.

5. Arif W, Shagufta W, Rizwan A. Sturge-Weber syndrome: A Review. Bombay Hospital Journal 2008; 50: 55-58. VJIM < Volume $17<$ July $2014<70$.

6. Takeoka M, Riviello JJ. Sturge-Weber syndrome. http://emedicine.medscape.com/article/1177523-overview.

7. Tarsila M et al. Sturge- weber syndrome case report. Odontilogia 2004: 3: 143-146.

8. ComiAM. Sturge-Weber syndrome and epilepsy: an argument for aggressive seizure management in these patients. Expert Rev Neurother 2007; 7: 951-956.

9. Sarah A. Sturge- Weber syndrome: A Review. Ann Indian Acad Neurol 2007; 10: 55-58.

10. Rochkind S, Hoffman HJ, Hendrick EB. Sturge-Weber syndrome: natural history and prognosis. J Epilep1990; 3: 293.

11. Thomas-Sohl KA, Vaslow DF, Maria BL. Sturge-Weber syndrome- a review. Pediatr Neurol, 2004 Vol. 30, (5), 303-310.

\section{AUTHORS:}

1. Shruti S. Patil

2. Ravi Raja Sankuri

\section{PARTICULARS OF CONTRIBUTORS:}

1. Assistant Professor, Department of Radio-diagnosis, M. R. Medical College, Gulbarga.

2. Post Graduate, Department of Radiodiagnosis, M. R. Medical College, Gulbarga.

\section{NAME ADDRESS EMAIL ID OF THE CORRESPONDING AUTHOR:}

Dr. Shruti S. Patil, \# 203, Lahoti Apartments, Station Road, Gulbarga-585102, Karnataka.

Email: drshrupatil@gmail.com

Date of Submission: 22/09/2014. Date of Peer Review: 23/09/2014. Date of Acceptance: 15/10/2014. Date of Publishing: 20/10/2014. 